\title{
Preliminary Imaging Results From the Second Mercury Encounter
}

\author{
Robert G. Strom, ${ }^{1}$ Bruce C. Murray, ${ }^{2}$ Michael J. S. Belton, ${ }^{3}$ G. Edward Danielson, ${ }^{4}$ Merton E. Davies, \\ Donald E. Gault, ${ }^{6}$ Bruce Hapke, ${ }^{7}$ Brian O'Leary, ${ }^{8}$ Newell Trask, ${ }^{9}$ John E. Guest, ${ }^{10}$ \\ JAmes ANDERSON, ${ }^{2}$ and KenNeth KLAASEN ${ }^{4}$
}

\begin{abstract}
The second Mercury encounter has resulted in the acquisition of about 360 pictures of the south polar regions which provide a reliable cartographic and geologic tie between the two sides of the planet photographed on the first encounter. Stereoscopic coverage of large areas of the southern hemisphere was obtained by combining Mercury 1 and 2 pictures taken at different viewing angles. The south polar regions consist of heavily cratered terrain and intercrater plains interspersed with patches of smooth plains. No large areas of smooth plains similar to those surrounding Caloris occur in the south polar regions. No new types of terrain have been recognized, but lobate scarps are common. The second largest basin seen by Mariner $10(\sim 600-\mathrm{km}$ diameter) has been confirmed on the new photography. At high solar elevations the surface displays an abundance of rays and rayed craters.
\end{abstract}

\section{INTRODUCTION}

The second Mercury encounter took place on September 21, 1974 , and provided a unique opportunity to view regions of Mercury under more favorable viewing geometry than was possible during the first encounter. Owing to constraints imposed by Mercury's rotation period and the orbital periods of the spacecraft and Mercury the second encounter occurred 6 months after the first when the terminator was in a position identical to that on the first encounter [Klaasen, 1975]. However, owing to severe foreshortening in the limb regions of the two sides of Mercury viewed on the first encounter it was not possible to interpret the structure in these areas or to make a geologic and cartographic tie between the two sides. Therefore a trajectory which allowed viewing of previously foreshortened regions was selected for the second encounter. In order not to preclude a third encounter it was necessary to target the second encounter to a bright side south polar pass (Figure 1). This trajectory allowed unforeshortened views of the south polar region and the exploration of areas not previously accessible for study. Owing to the small field of view $\left(0.37^{\circ} \times 0.48^{\circ}\right)$ resulting from the long focal length telescopes $(1.5 \mathrm{~m})$ it was necessary to increase the periapsis altitude to about $48,000 \mathrm{~km}$ in order to insure sufficient overlapping coverage to make a reliable geologic and cartographic tie. Although this large miss distance meant a sacrifice in resolution, it was considered more important to obtain the greater coverage necessary to make the tie and broadly explore this region. The resolution of the photography taken during the encounter phase $(-3$ to +3 hours) ranges from 1 to $3 \mathrm{~km}$, with all coverage of the previously foreshortened regions between 1 - and 1.5$\mathrm{km}$ resolution. Figure 2 is an airbrush rendition of the coverage obtained on the first encounter. The diagonal line

${ }^{1}$ University of Arizona, Tucson, Arizona 85721.

${ }^{2}$ California Institute of Technology, Pasadena, California 91109.

${ }^{3}$ Kitt Peak National Observatory, Tucson, Arizona 85726.

4 Jet Propulsion Laboratory, Pasadena, California 91103.

- Rand Corporation, Santa Monica, California 90401.

${ }^{8}$ Ames Research Center, Moffelt Field, California 94035.

${ }^{7}$ Universily of Pittsburgh, Pittsburgh, Pennsylvania 15260.

- Hampshire College, Amherst, Massachusetts 01002.

- U.S. Geological Survey, Reston, Virginia 22092.

${ }^{10}$ University of London Observatory, London, England.

Copyright (c) 1975 by the American Geophysical Union. pattern indicates the coverage between $1-$ and $1.5-\mathrm{km}$ resolution resulting from the second encounter. Although spacecraft limit cycling produced gores in some of the mosaics, the coverage was redundant enough to provide a good geologic and cartographic tie between the two sides of the planet previously viewed by Mariner 10 [Davies and Batson, 1975]. In Figure 3 a single picture taken with the wide angle lens (focal length, $50 \mathrm{~mm}$ ) near closest approach is compared with the inbound and outbound mosaics taken on the first encounter. Several features common to areas photographed on both encounters are indicated. Numerous pictures were taken over a 5-day period around encounter for optical navigation tests and calibration purposes in addition to the 360 frames taken during the encounter phase. The detailed imaging sequence of the second encounter, as well as the preliminary mosaics, is presented by Danielson et al. [1975].

The primary objectives of the second encounter were (1) to provide a geologic and cartographic tie in the southern hemisphere between the two sides of Mercury photographed on the first encounter, (2) to search for terrain or structural types not previously seen on the first-encounter photography and to determine the extent of previously recognized types, (3) to search for basins within the size range $450-1300 \mathrm{~km}$ which were not obviously in evidence on the first-encounter pictures, (4) to obtain stereoscopic coverage of a large portion of the southern hemisphere for quantitative topographic information, (5) to view the planet at a different phase angle to improve photometric studies, and (6) to confirm or modify interpretations based on the first-encounter data by extending the photographic coverage.

The general results from a preliminary examination of the second-encounter pictures are presented in the following section. Some of the more specific results and several individual frames are contained in the papers making up this issue.

\section{Preliminary Results}

In general, the south polar regions of Mercury resemble the inbound side viewed on the first encounter. The surface is pockmarked with craters ranging in size up to basin dimensions (Figures 4-10). Two types of terrain dominate this portion of the planet: heavily cratered terrain and intercrater plains [Trask and Guest, 1975]. The morphology and stratigraphic relationships of these terrain types are essentially identical to those in other parts of Mercury as described by Trask and Guest [1975]. Interspersed with the cratered terrain 

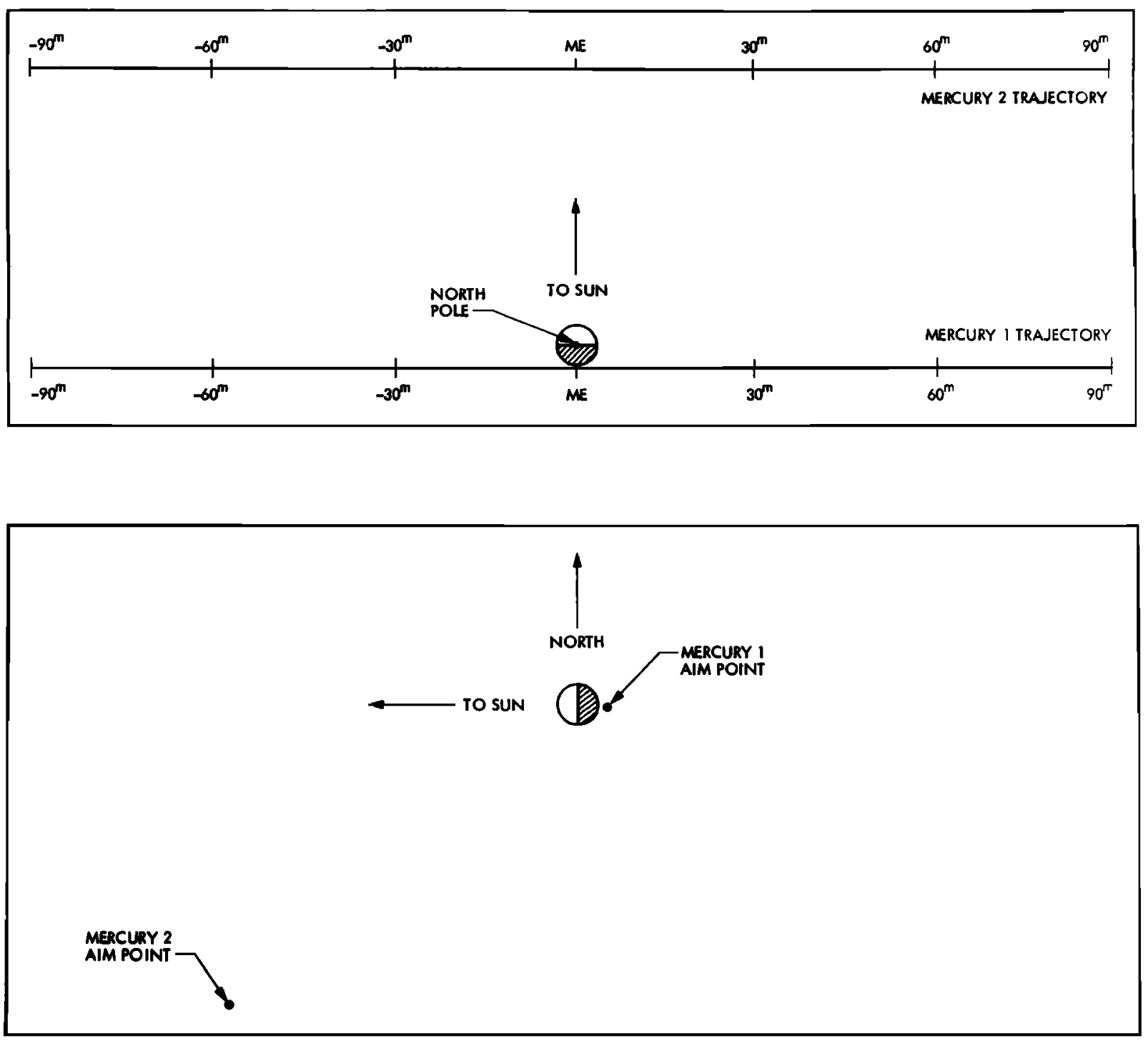

Fig. 1. Diagram of the trajectories of the first and second Mercury encounters as seen (top) normal and (bottom) parallel to the spacecraft trajectory. The numbers in the upper diagram represent the time in minutes before or after Mercury encounter (ME). The closest approach of the first encounter was about $700 \mathrm{~km}$, while that of the second encounter was about $48,000 \mathrm{~km}$.

and intercrater plains are patches of younger smooth plains similar in appearance to those on other parts of the planet. Some of this material fills the interiors of the basins and craters, while some occurs between craters. No large areas of smooth plains similar to those surrounding the Caloris or Borealis (north) basins are present in this region of the planet. On the portion of Mercury viewed by Mariner 10 the smooth plains are concentrated in the northern hemisphere between $0^{\circ}$ and $90^{\circ} \mathrm{N}$ and about $120^{\circ}$ and $190^{\circ} \mathrm{W}$. Mercury therefore appears to exhibit an asymmetric distribution of plains, as do the moon and Mars.

Several large basins which were severely foreshortened or were not seen on the first-encounter pictures occur in the southern hemisphere (Figures 4, 7, 8, and 9). These basins range from 200 to $600 \mathrm{~km}$ in diameter and are floored with smooth plains material. The smaller basins usually have two well-preserved rings with the diameter of the outer ring about twice that of the inner ring. These multiring basins appear to be very common on Mercury. Figure 4 shows three such basins about $200 \mathrm{~km}$ in diameter. The largest basin seen on the second-encounter photography is about $600 \mathrm{~km}$ in diameter and is centered at $17^{\circ} \mathrm{S}, 118^{\circ} \mathrm{W}$ (Figure 8). This basin is about half the size of Caloris and is the second largest structure seen by Mariner 10. Its presence was suspected on the first-encounter pictures, but owing to a combination of poor viewing geometry and lighting conditions it was difficult to be sure of its existence. Although the high solar elevation $\left(\sim 70^{\circ}\right)$ makes this basin more difficult to discern than other basins closer to the terminator, the rim is fairly easy to detect, as is seen in Figure 8. The basin is filled with smooth plains which have been moderately cratered by subsequent large impacts. Traces of radial sculpturing are visible to the southeast of the basin, where they consist primarily of crater chains $150-180 \mathrm{~km}$ long and about $12 \mathrm{~km}$ wide. However, most of this radial structure has been obliterated by later cratering. Along the western rim of the basin there appears to be a lobate scarp which forms the boundary between the floor material and the rim as sometimes occurs in other mercurian basins [Strom et al., 1975]. The degree of degradation and the crater density on the floor and surroundings of this basin suggest that it is comparable in age to the $380-\mathrm{km}$ basin shown in Figure 7. This large basin fills the apparent size gap between $450 \mathrm{~km}$ and $1300 \mathrm{~km}$ which was 
inferred from the first-encounter photography [Murray et al., 1974].

Although high solar elevations inhibit the recognition of structure, they are very useful for detecting albedo differences, in particular, crater rays. Figure 9 is a second-encounter mosaic showing the surface under high solar illumination. Numerous rayed craters ranging in size from $56 \mathrm{~km}$ down to the resolution of the pictures $(\sim 1 \mathrm{~km})$ are scattered across the surface. Several large rays with no evident source also traverse the surface. The interior rims of many craters are bright, suggesting that slumping has exposed newer surfaces, as has occurred on the moon. In general, the appearance of Mercury at high solar elevations is similar to that of the lunar highlands viewed under equivalent lighting conditions.

No new terrain types have been identified on the second- encounter pictures. The peculiar hilly and lineated terrain is not evident in the south polar regions, although at high solar elevations it would be difficult to identify. The apparently unique location of this type of terrain antipodal to the Caloris basin strengthens the speculation that its origin is due to seismic effects of the Caloris impact [Schultz and Gault, 1974].

Lobate scarps are prevalent in the south polar regions. Several of these features are indicated in Figures 5-7. Their morphology and transection relationships are virtually identical to those seen on the first-encounter pictures. One of these scarps (Figure 7) is over $\mathbf{4 0 0} \mathbf{~ k m}$ long and transects at least three craters. Others range in length from $300 \mathrm{~km}$ down to about $50 \mathrm{~km}$ or less. The abundance of these structures on the second-encounter photography, together with their relatively uniform distribution on the first-encounter mosaics,

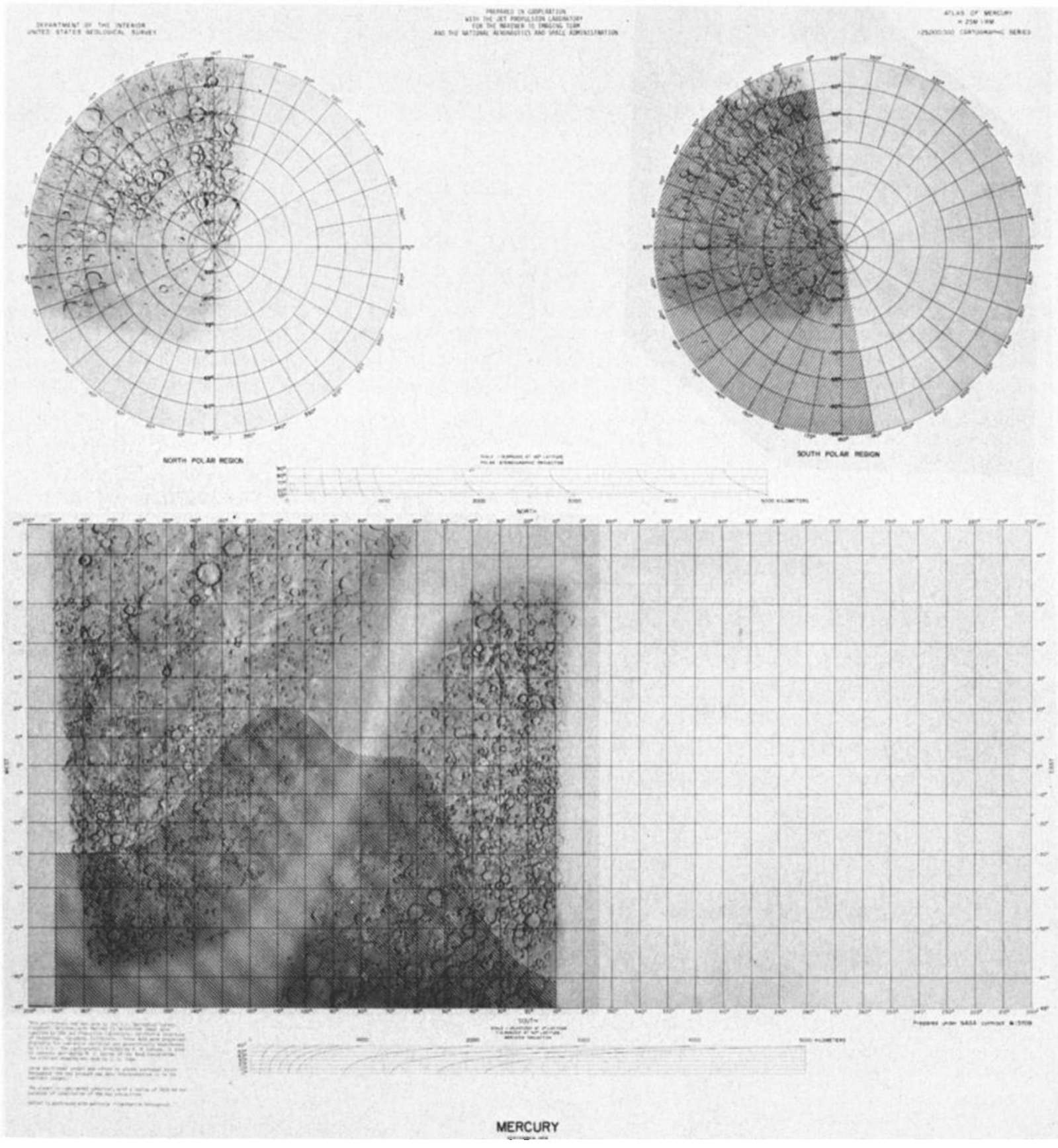

Fig. 2. Airbrush rendition of the coverage obtained on the first encounter with the Mercury 2 coverage between I-km and $1.5-\mathrm{km}$ resolution indicated by the diagonal line pattern. 


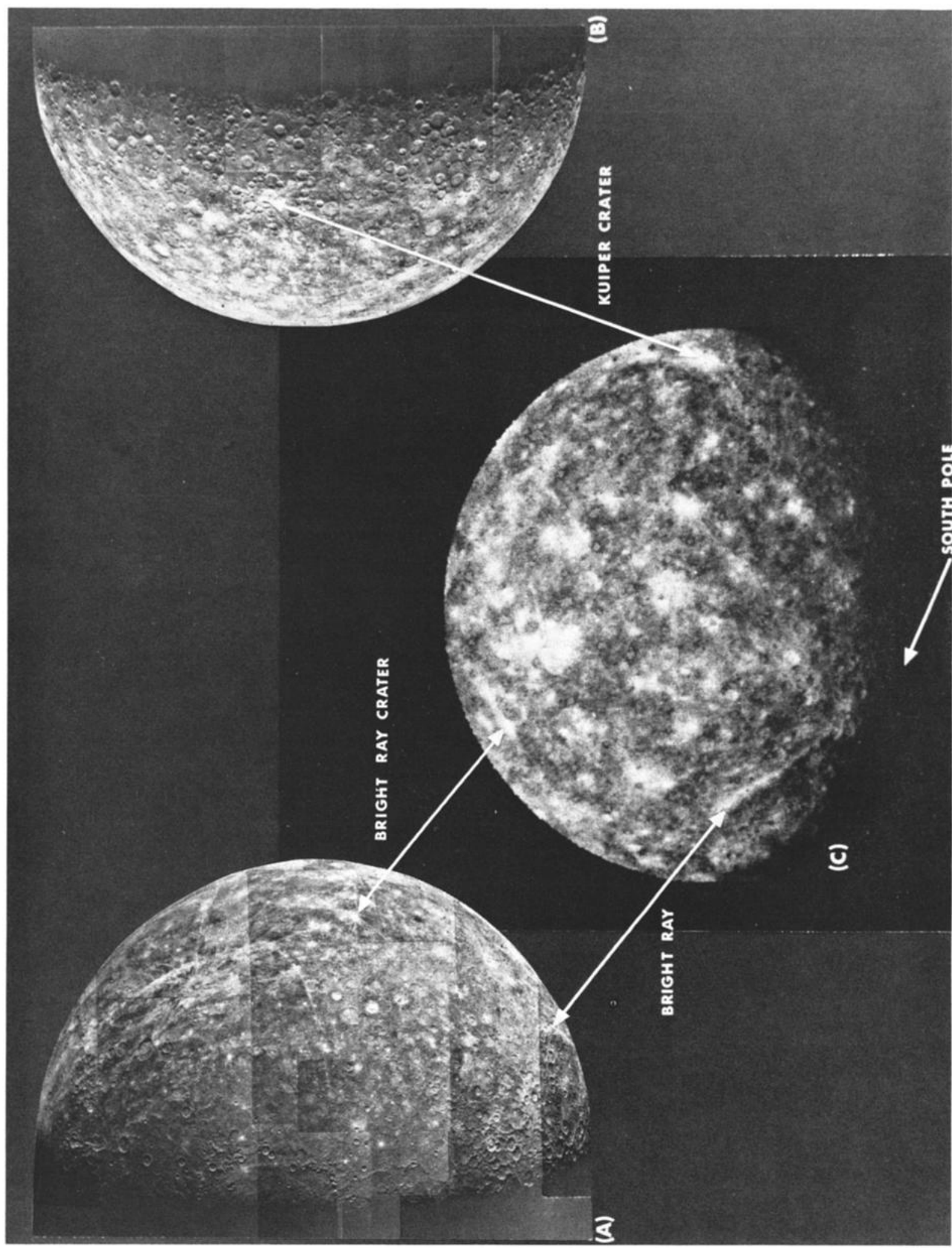

章

흥

量

ड़

象

势

氖

害要

退

क्षे

要

垔

空

宫

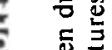

远

$\vec{\pi}$

焉焉

$\sum_{i}^{\infty}$

$\sum_{i} \dot{\Phi}$

政

过

部

要

항

寻

氖

등

등

苍迨

흥

可部

은

응

\&

胥

응

항.

\%

응.

ह.

U원

m

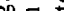

类总 


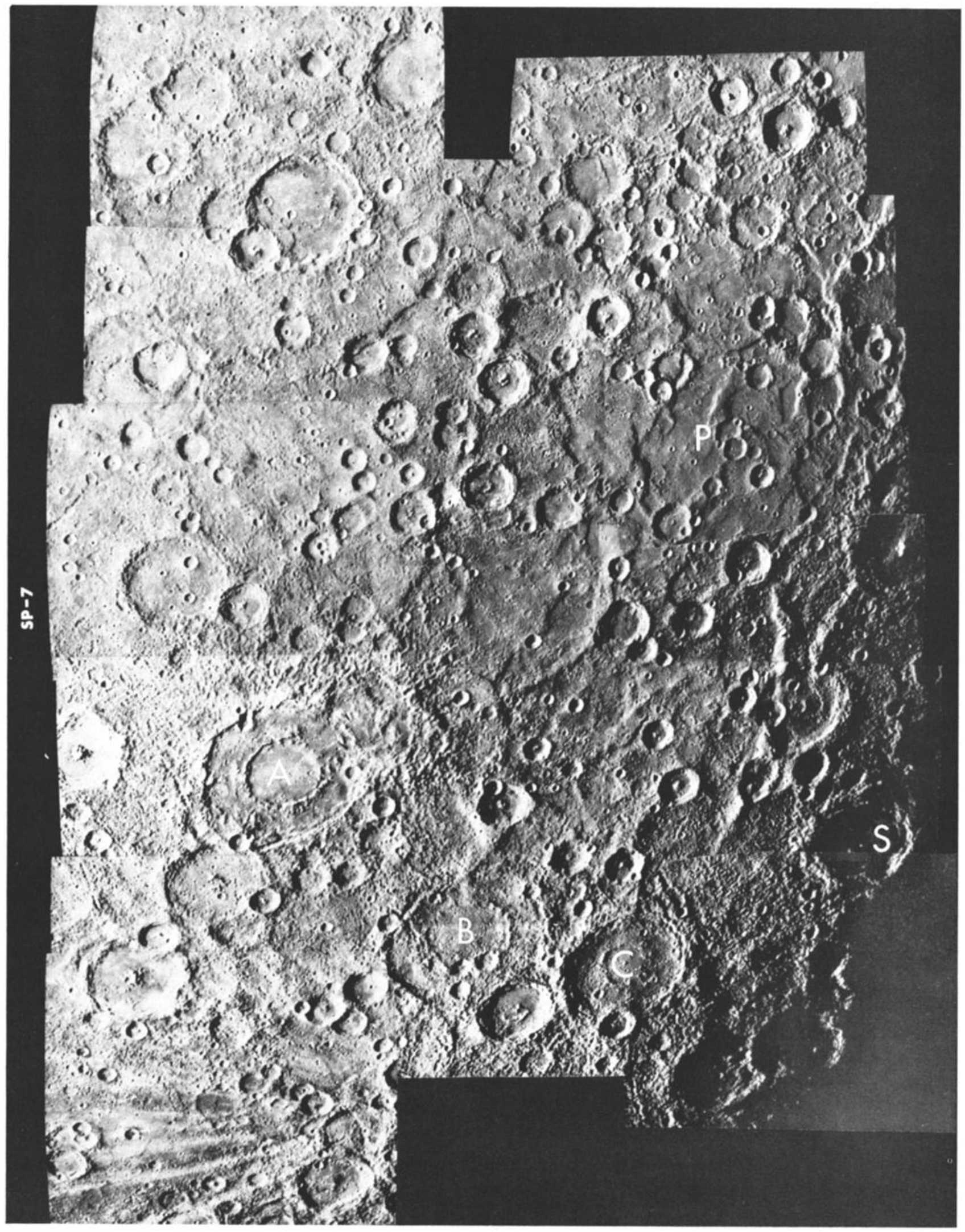

Fig. 4. Second-encounter mosaic showing three double-ringed basins (A, B, and C). Basin A is $200 \mathrm{~km}$ in diameter and exhibits a well-developed ejecta blanket with numerous secondary craters, some of which cross basin $B$. An area $(P)$ about $400 \mathrm{~km}$ in diameter contains smooth and intercrater plains and is crossed by numerous ridges and scarps. The approximate location of the south pole is indicated by $S$. 


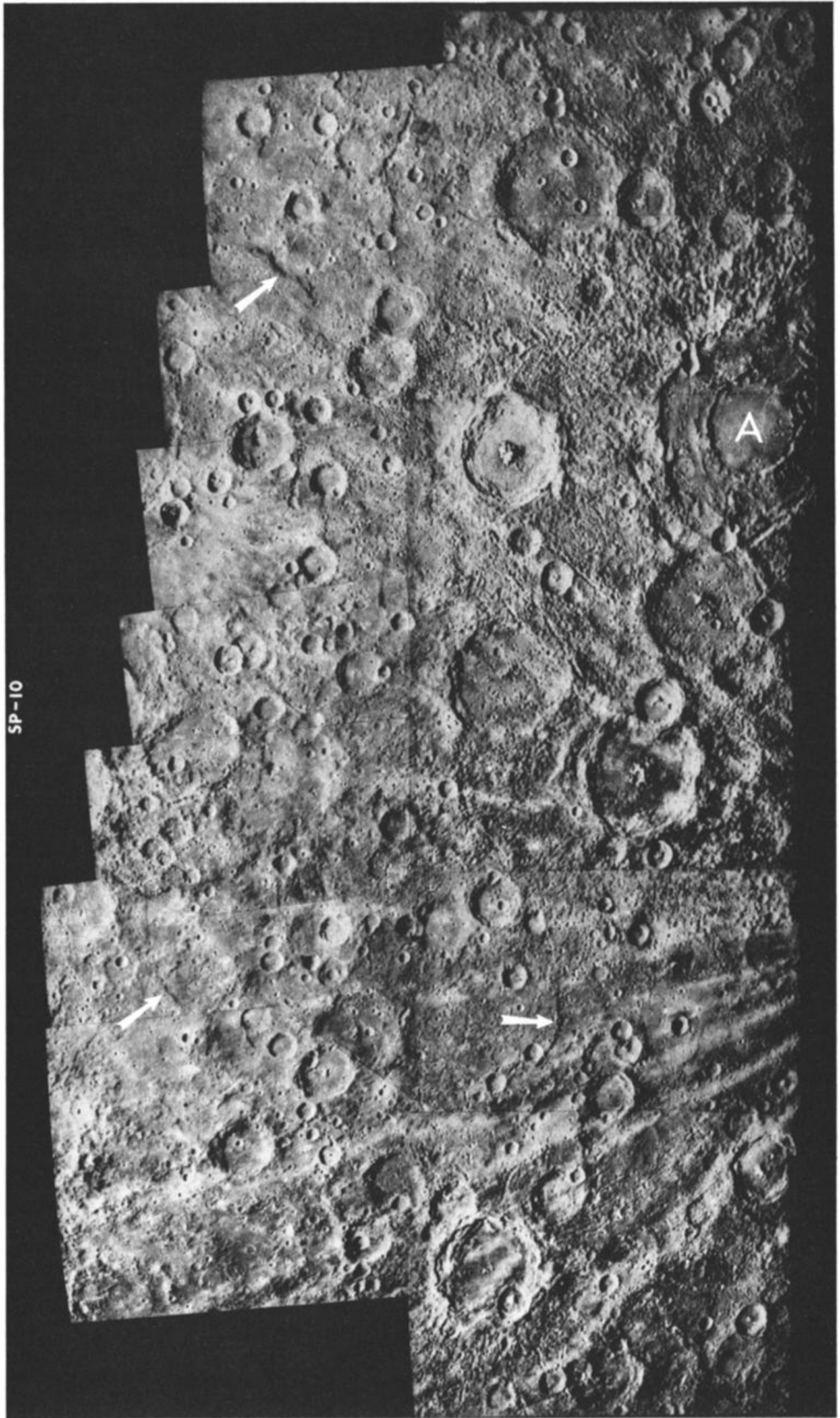

Fig. 5. Mercury 2 mosaic of the typical heavily cratered surface in the south polar regions. The double-ringed basin (A) is the same as that indicated in Figure 4. The prominent crater with the massive central peak to the left of basin $A$ is about $100 \mathrm{~km}$ in diameter. The long rays crossing the surface radiate from the 53-km-diameter crater shown in Figure 6. Several lobate scarps are indicated by arrows. 


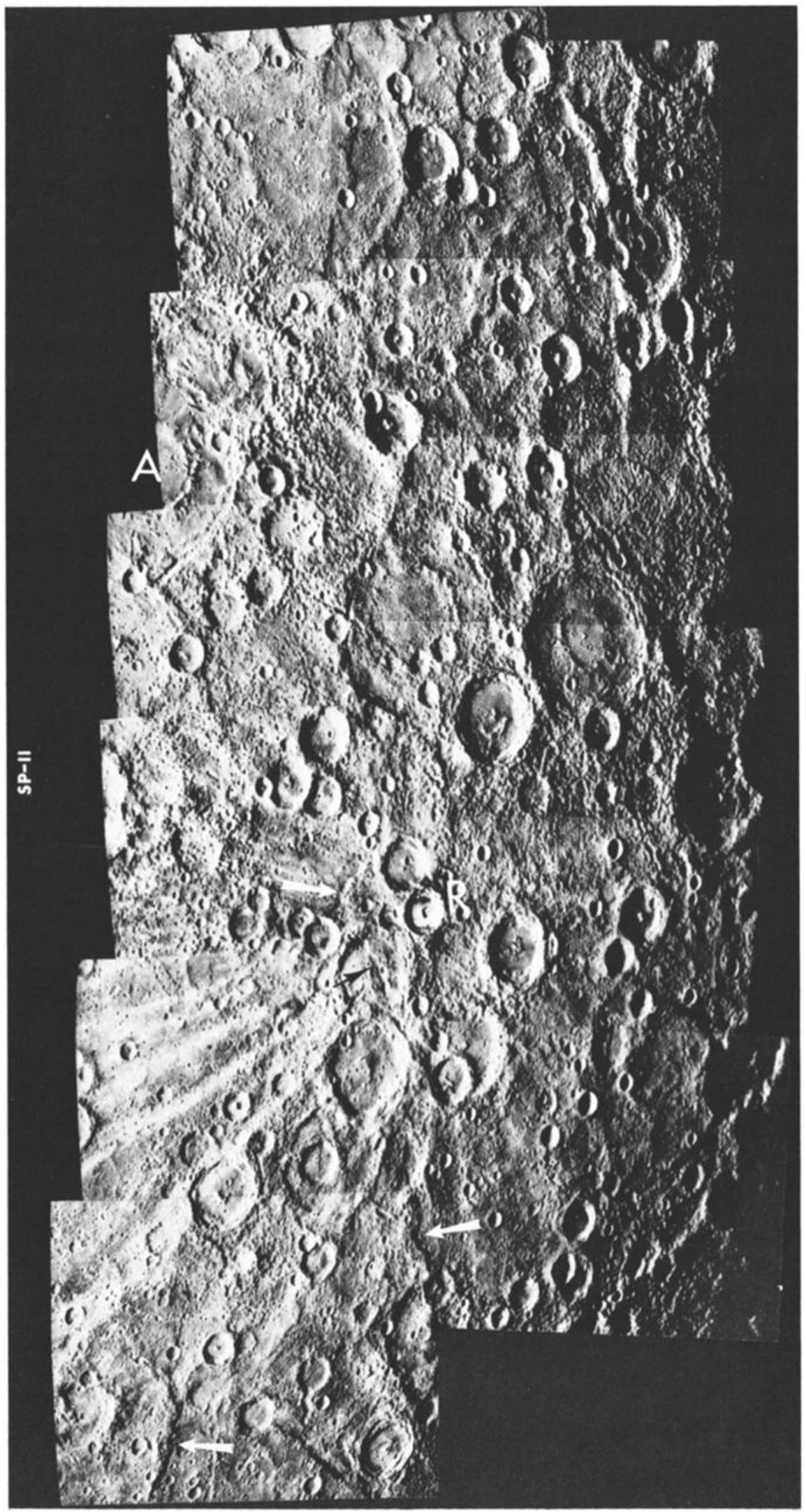

Fig. 6. Region adjacent to that shown in Figure 5 displayed in this Mercury 2 mosaic. The crater (R) is about $53 \mathrm{~km}$ in diameter and shows numerous bright rays which radiate for distances well over $800 \mathrm{~km}$. Many of these rays cross the area shown in Figure 5. Several lobate scarps are indicated by arrows. Basin A is the same as that indicated in Figures 4 and 5. 


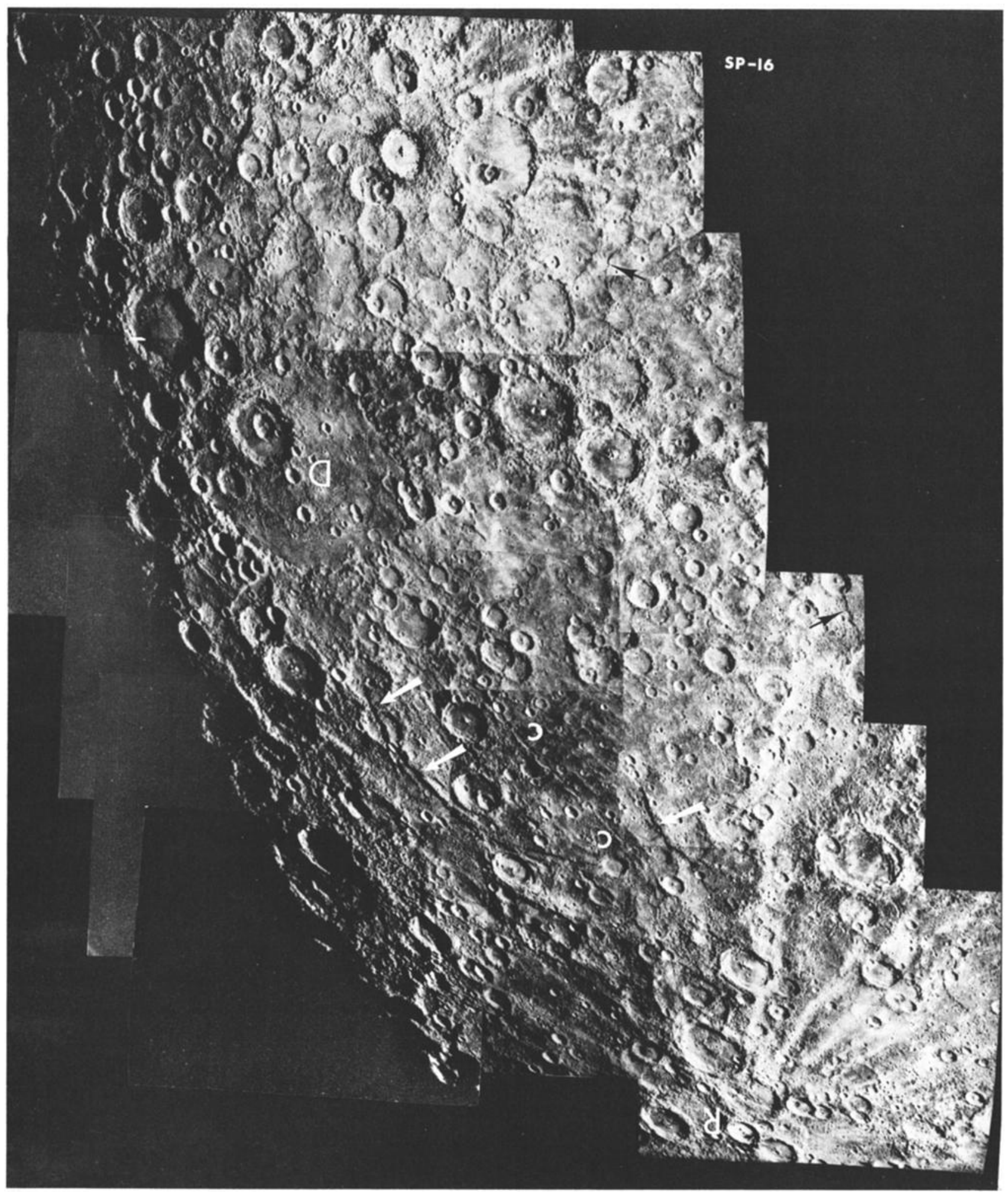

Fig. 7. Mercury 2 mosaic centered at about $60^{\circ} \mathrm{S}$ and $160^{\circ} \mathrm{W}$ and showing an area which was severely foreshortened on the first encounter. The large basin (D) is about $380 \mathrm{~km}$ in diameter and is filled with smooth plains. A crater chain (C) is oriented radially to the basin and may be secondary impacts due to material ejected from the basin. The rayed crater $(R)$ at the top of the mosaic is the same as that noted in Figure 6. Several large lobate scarps are indicated by arrows. The large scarp (two arrows) south of the basin is about $400 \mathrm{~km}$ long. This mosaic is oriented with south at the top. 


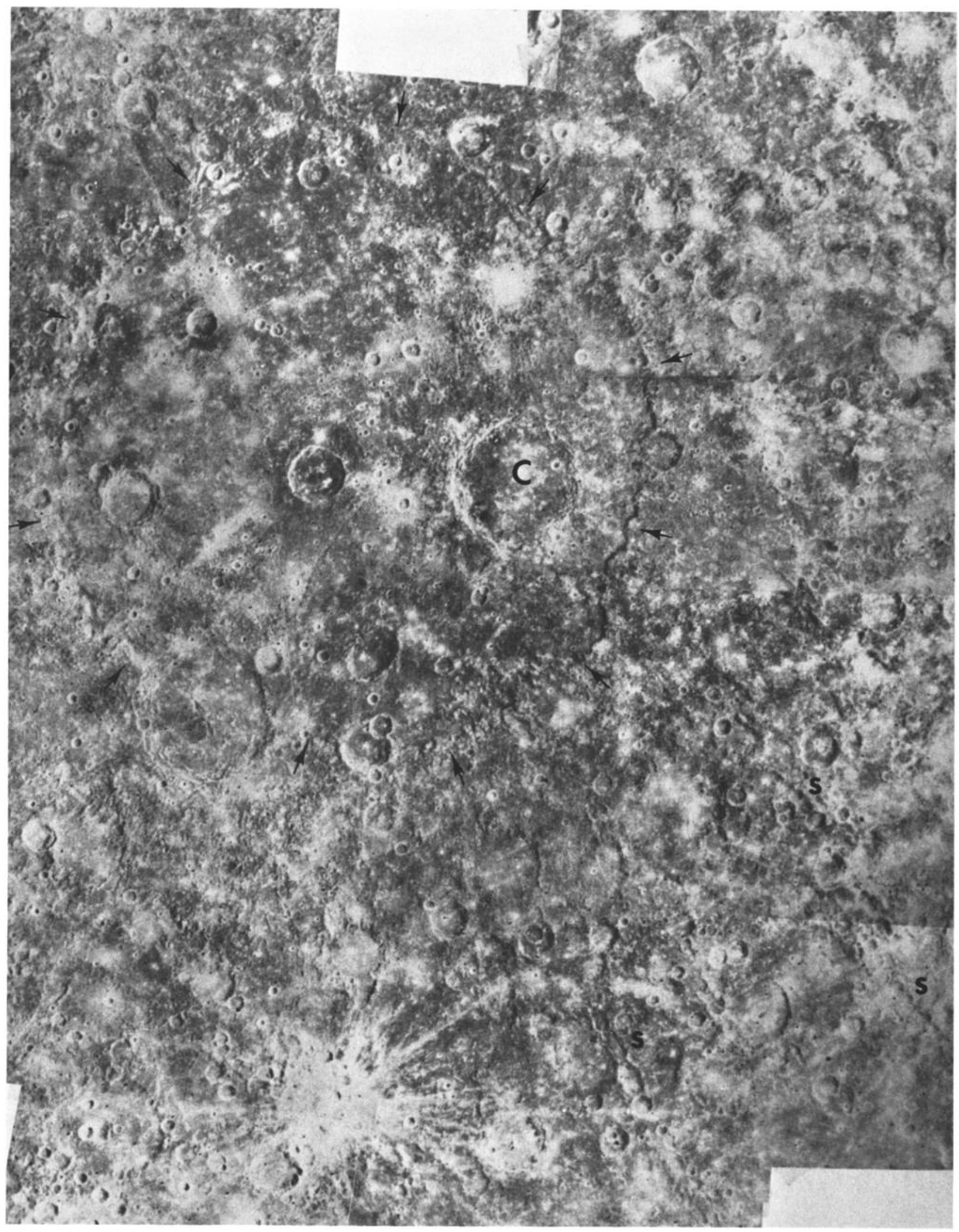

Fig. 8. Mercury 2 mosaic of a large basin about $600 \mathrm{~km}$ in diameter. The basin rim is indicated by arrows. The basin appears to be filled with smooth plains which have subsequently been impacted by rather large objects. The large crater (C) near the eastern rim is about $110 \mathrm{~km}$ in diameter. Remnants of radial sculpturing (S) similar to that around Caloris can still be discerned to the southeast of the basin. This radial pattern seems to consist primarily of crater chaıns similar to the one indicated south of the $380-\mathrm{km}$ basin in Figure 7. 


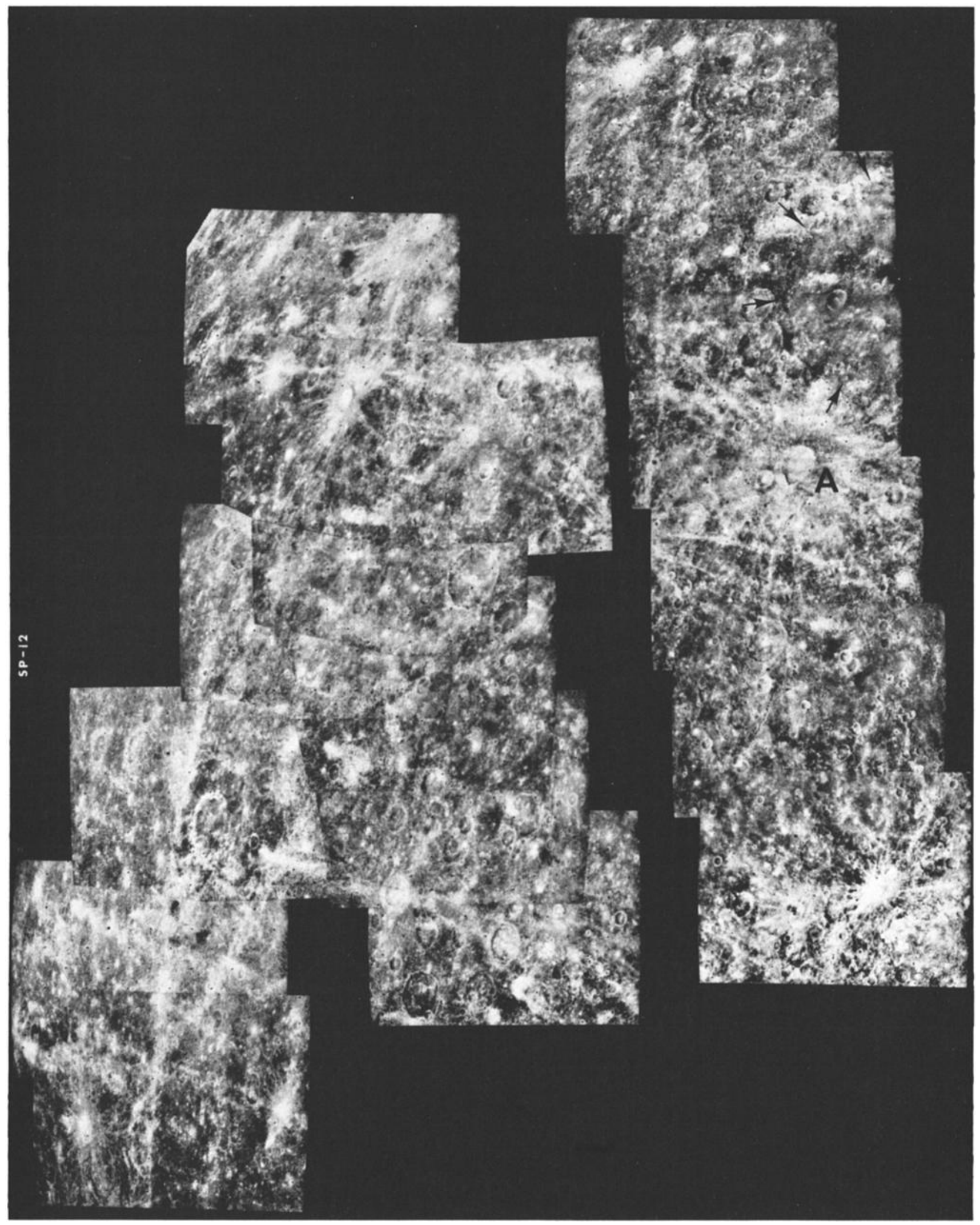

Fig. 9. Surface of Mercury seen under high solar elevations in this Mercury 2 mosaic and showing an abundance of rayed craters. The large rayed crater $(A)$ is $56 \mathrm{~km}$ in diameter. A large basin about $360 \mathrm{~km}$ in diameter is located above the rayed crater, its rim being indicated by arrows. Part of the limb of the planet can be seen in the upper left corner of the mosaic. 


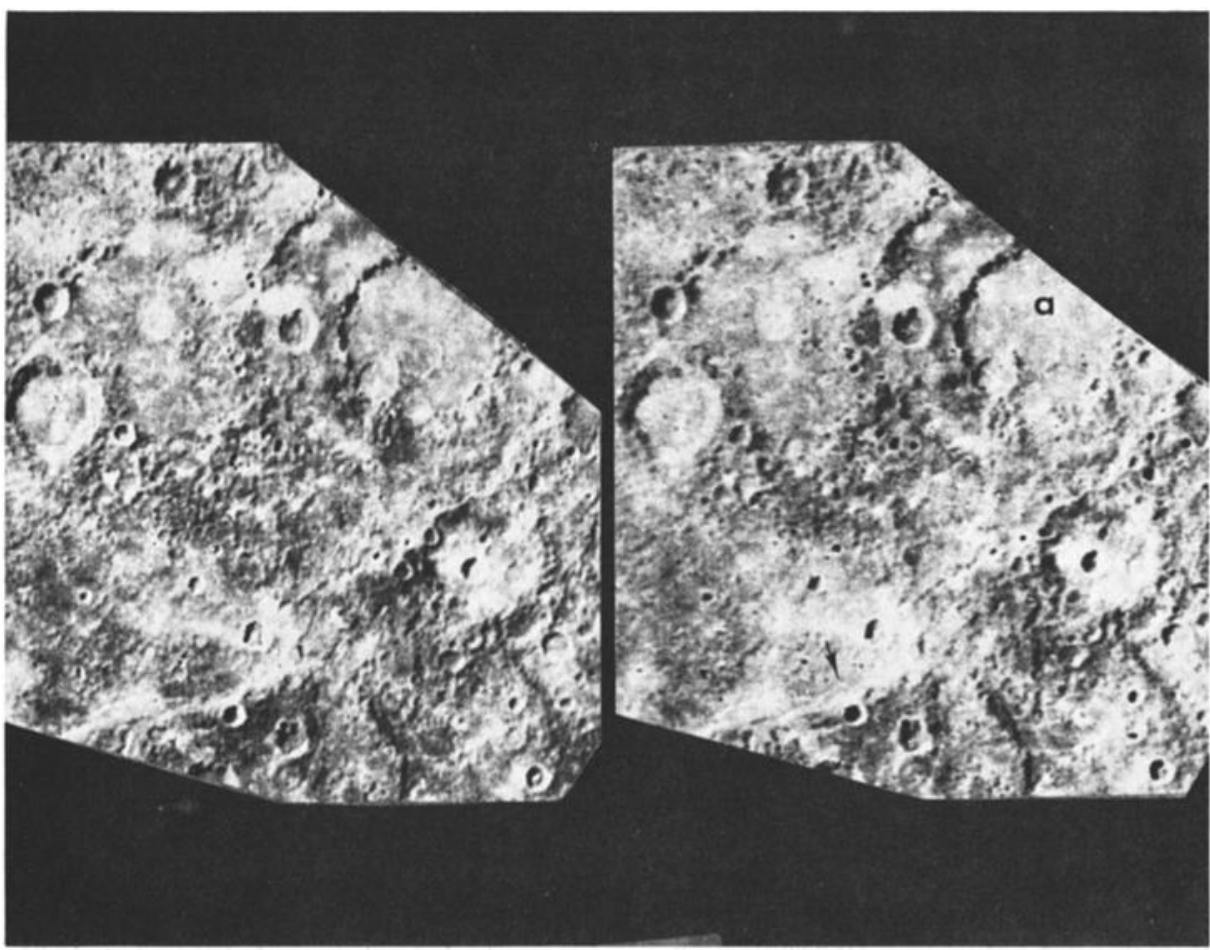

Fig. 10. Typical stereo pair taken on the (right) first and (left) second encounters of an area centered about $38^{\circ} \mathrm{S}$, $62^{\circ} \mathrm{W}$. The pictures have been rectified to an orthographic projection, and their scales equalized. The double-ringed basin (a) is $200 \mathrm{~km}$ in diameter. A portion of a large lobate scarp is indicated by the arrow. (Right) FDS27301. (Left) FDS166649.

strengthens the suggestion that these features have a global distribution resulting from a general compression of the outer regions of the planet [Strom et al., 1975].

An extremely valuable result of the second encounter was the acquisition of stereoscopic coverage over large portions of the southern hemisphere. Since the trajectories of the two encounters past Mercury were so different (Figure 1), large areas photographed on the first encounter were seen at significantly different viewing angles on the second encounter. Furthermore, owing to the changing viewing geometry and redundant coverage, many areas were viewed separately at different angles on the second encounter alone. Preliminary tests show excellent stereoscopy at separation angles of about $15^{\circ}$ or larger. Much of the redundant coverage was taken at these separation angles. Since the illumination conditions were identical on both encounters, there is no difference in shadow lengths to impair stereoscopic viewing. Figure 10 is a representative stereo pair consisting of pictures taken on the first and second encounters at a separation angle of about $47^{\circ}$. The pictures have been rectified to an orthographic projection, and their scales equalized. The double-ringed basin ( $a$ on Figure 10 ) is about $200 \mathrm{~km}$ in diameter and is floored with smooth plains material. Stereoscopy dramatically shows that the floor within the inner ring is at a considerably lower level than the surface between the inner and the outer rings. Also, the surface behind the lobate scarp slopes away from the scarp for a distance of about $40 \mathrm{~km}$. Other interesting relative heights and slopes which would be difficult or impossible to determine from monoscopic viewing can be identified on this stereo pair. Stereoscopic coverage such as this will be an invaluable tool for height determinations as well as topographic, stratigraphic, and structural relationships. Stereoscopic viewing of areas photographed at high solar angles will be particularly useful because surface structure is difficult or impossible to identify under these lighting conditions with monoscopic viewing.

\section{SUMMARY}

The pictures of the south polar regions resulting from the second encounter have provided the coverage necessary to make a reliable geologic and cartographic tie between the two sides of Mercury seen on the first encounter. An added bonus was the acquisition of stereoscopic coverage over large areas of the southern hemisphere, which will be extremely valuable in deciphering mercurian topographic, stratigraphic, and structural relationships.

In general, the south polar regions consist of a heavily cratered surface very similar in appearance to the inbound side seen on the first encounter. The surface is crossed by numerous rays, some being without evident sources, and shows an abundance of rayed craters when it is viewed under high solar elevations. It is very similar in appearance to the lunar highlands viewed under similar illumination conditions. The second largest basin viewed by Mariner $10, \sim 600 \mathrm{~km}$ in diameter, has been confirmed on the second-encounter photography. This basin is filled with smooth plains and is older than the Caloris basin as evidenced by the number of large craters on its rim and floor. Lobate scarps are abundant in the south polar regions and support the concept that an early episode of global compression has occurred on Mercury. To date, nothing has been seen on the second-encounter photography which would seriously alter the interpretations based on the first-encounter pictures. On the contrary, the presence of lobate scarps and several stratigraphic relationships involving plains material seem to strengthen those interpretations. However, it should be kept in mind that the stereoscopic data have not yet been analyzed and will undoubtedly provide an extremely impor- 
tant insight into mercurian surface processes which could alter some of the interpretations made to date. There is little doubt that the second encounter has provided a wealth of new information about the surface of Mercury which will enhance and expand our knowledge of this interesting planet.

Acknowledgments. We gratefully acknowledge the support and encouragement of the National Aeronautics and Space Administration and specifically the untiring support of $W$. Cunningham and $S$. Dwornik, the Program Manager and Program Scientist, respectively. We extend sincere appreciation and thanks to the many individuals at the Jet Propulsion Laboratory (JPL) and the Boeing Company, who contributed to the success of the Mariner 10 second encounter. J. Soha and J. Mosher of JPL expertly chose optimum parameters for image processing and projections for stereoscopic viewing. In particular, the TV team is indebted to Ken Klaasen, JPL Imaging Experiment Representative, whose planning and execution of the TV sequence were fundamental to the success of the second encounter.

\section{REFERENCES}

Daniejson, G. E., K. Klaasen, and J. Anderson, Acquisition and description of the Mariner 10 television science data at Mercury, $J$. Geophys. Res., 80, this issue, 1975.

Davies, M. E., and R. M. Batson, Surface coordinates and cartography of Mercury, J. Geophys. Res., 80, this issue, 1975.

Klaasen, K., Mercury rotation period determined from Mariner 10 photographs, J. Geophys. Res., 80, this issue, 1975.

Murray, B. C., et al., Mercury's surface: Preliminary description and interpretation from Mariner 10 pictures, Science, 185, 169, 1974.

Schultz, P., and D. Gault, Seismic effects from major basin formation on the moon and Mercury, NASA Tech. Memo. X-62, 388, 1974.

Strom, T., N. Trask, and J. Guest, Tectonism and volcanism on Mercury, J. Geophys. Res., 80, this issue, 1975.

Trask, N., and J. Guest, Preliminary geologic terrain map of Mercury, J. Geophys. Res., 80, this issue, 1975.

(Received February 14, 1975;

revised February 27, 1975;

accepted March 3, 1975.) 